\title{
Interactive comment on "PlioMIP2 simulations using the MIROC4m climate model" by Wing-Le Chan and Ayako Abe-Ouchi
}

\section{Anonymous Referee \#2}

Received and published: 24 March 2020

This manuscript presents initial results from the MIROC4m modelling group for 8 experiments according to the PlioMIP 2 design. All these simulations have been integrated for long term. The analysis work is sufficient and logical, some previous PlioMIP2 studies have been discussed with their outputs. This is a solid contribution to the PlioMIP2 effort. I recommend publication of this paper with considering the minor suggestions listed as below:

General comments: 1 . The authors have included the EPlio1 experiment in the present study to compare with the PlioMIP2 core experiment. However, it lacks broadly discussion about the difference between these two experiments with regards to the SAT, SST, precipitation and sea ice. The Eplio1 differs from the PlioMIP2 not only in the topography, which is moslty mentioned in the results, but also in the land-sea mask, the lakes

Printer-friendly version

Discussion paper 
in the Africa as well as the soil types. I suggest the authors could pay more attention with regards to these aspects.

2. Section 4.6: The Meridional heat transport have been studied in many PlioMIP 2 papers (Li et al.,2020, Chandan and Peltier et al.,2017, Tan et al.,2020, Feng et al.,2020 etc). I suggest the authors can compare the results with the others. According to Figure 13, it is worth noting that the import change appears over the low latitudes which is different from the aforementioned studies. By the way, Figure 13 is not easy to read, I suggest to put all the absolute values in one plot.

3. Section 4.7: I do not understand why the authors compare the E280 with the proxy data reconstructed for the mid-Pliocene and discuss the performance of the data-model fit of the Pliocene experiment and the Pliocene experiment together (line 316). Section 4.8: I suggest the authors could also compare the model outputs with the PRIMS4 data (Foley and Dowsett, 2019) which is more specific for the PlioMIP phase 2.

Specific comments:

1. Line 145: Confused. Please specify which 4 experiments are further integrated for another 1000 years and why they need to be integrated for another 1000 years . 2. Line 155: Why are the greenhouse gases not changed to be PlioMIP level in the first 3000 years run ? 3. Line 167: In my opinion, figure 3a does not approve "Temperature increase fairly uniformly", In figure 3a, the warming amplitude over high latitudes is stronger than the low latitudes, the land warming is larger than the ocean broadly, and some extreme warming regions are found in the Barents sea and around coastal regions of the Antarctic. 4. Line 184: Compared to the PlioMIP1, PlioMIP2 also modify the Bering strait and Northern Canadian Archipelago regions, do they have any impacts on this different warming ? 5. Line 196:"near-uniform increase outside the polar regions" is not appropriate, according to Figure 4, I suggest to be "near-uniform increase outside the low latitudes (30N-30S)". 6. Line 194: What is the "bias" here ? 7. Line 205: What is the reason for the seasonal change of the artic region, is the sea ice

Interactive comment

Printer-friendly version

Discussion paper 
fraction change responsible for that ? 8. Line 221: What is the potential reason for the SST anomalies for the other regions, e.g. the Labrador sea, the North Atlantic Ocean ?

Interactive comment on Clim. Past Discuss., https://doi.org/10.5194/cp-2020-17, 2020.

CPD

Interactive comment 